\title{
Dr. Google, what can you tell me about homeopathy? Comparative study of the top10 websites in the United States, United Kingdom, France, Mexico and Spain
}

\author{
Lorena Cano-Orón
}

Nota: Este artículo se puede leer en español en:

http://www.elprofesionaldelainformacion.com/contenidos/2019/mar/05_es.pdf

How to cite this article:

Cano-Orón, Lorena (2019). "Dr. Google, what can you tell me about homeopathy? Comparative study of the top10 websites in the United States, United Kingdom, France, Mexico and Spain". El profesional de la información, v. 28, n. 2, e280213.

https://doi.org/10.3145/epi.2019.mar.13

Article received on 08 Nov. 2018 Approved on 31 Jan. 2019

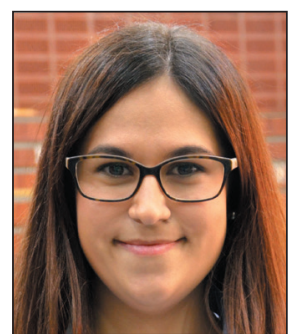

Lorena Cano-Orón $\bowtie$

https://orcid.org/0000-0003-4270-1924

Universidad de Valencia

Facultad de Filología, Traducción y Comunicación

Dpto. de Teoría de los Lenguajes y Ciencias de la Comunicación

Avda. Blasco Ibáñez, 32- 5a planta

46010 Valencia, Spain

lorena.cano@uv.es

\begin{abstract}
Users access to Google to find out about health issues is frequent among citizens. This research analyzes the best results of three generic searches on homeopathy, collected in four waves in five countries: Spain, France, Mexico, the United Kingdom, and the United States. Specifically, the fluctuation of the corpus ranking is studied, and a sample of the ten best-positioned pages in each country is taken to analyze their content (the authorship of the website, the stance of the effectiveness of homeopathy, the presence of controversy and the type of content). The results show that the ranking is stable; that the stance of homeopathy is linked to the state of public opinion in the country; and that the majority of websites that appear better-positioned are from media.
\end{abstract}

\section{Keywords}

Search engines; Information search; Algorithms; SERP; Rankings; Biases; Google; Web sites; Health; Health information; Homeopathy.

\section{Financial information}

The present work has been developed within the framework of the research project "Study and classification of natural, complementary and alternative therapies through media and social networks. Transference ideas and values applied to the social imaginary" (CSO2014-57778-R), financed by the Spanish Ministry of Science, Innovation and Universities and co-financed with the European Social Fund.

\section{Acknowledgements}

The author wishes to thank Carolina Moreno Castro and Guillermo López García for the support and feedback received during the preparation of this manuscript; to Isabel Mendoza-Poudereux for her indispensable collaboration in the reliability test of coding; and Fran García Ull for his advice with Google Ads. Finally, this work was propelled by the advice received in the Doctoral Summer School: Digital journalism and media convergence: theories and methodologies, in particular the one received from Professor Lluís Codina. 


\section{Introduction}

One in twenty searches conducted on Google focuses on health-related information (Ramaswami, 2015). These types of searches are usually anecdotally called "Dr. Google" (Pías-Peleteiro; Cortés-Bordoy; Martinón-Torres, 2013; Van-Riel et al., 2017), due to the kind of doubts with which the search engine is accessed. The order in which Google offers the search results in its results pages (SERP, search engine result pages) is due to a series of hierarchical factors determined by algorithms.

This automation of the evaluation and ordering of the webs, whose exact procedure is secret, makes us consider Google as a gatekeeper of the information.

Users tend to focus on the first results of the ranking (Gonzalo-Penela, 2015; Lee, 2005), so, logically, this ranking of search results is key to solving the user's demands. This order is not usually questioned by users

One in twenty searches conducted on Google focuses on health-related information

(Lewandowski, 2017), who trust the relevance of the results (Noble, 2018), so that the selection of webs that appear first can have an important influence on them (Pogacar et al., 2017; Arif et al., 2018; Allam; Schulz; Nakamoto, 2014; Pan et al., 2007).

When searching a controversial health issue, whether at the scientific or social level, the type of content and the position on the topic of the best positioned websites have a determining potential to form the user's opinion (Pogacar et al., 2017; Germano; Sobbrio, 2017). The variety of points of view in the ranking seems to be related to the popularity of the topic in the public opinion (Gerhart, 2004).

This research takes as a case study the access to information on homeopathy, an unconventional therapy that has captured the attention of public opinion in Spain in the last two years and that in the media field is being increasingly treated with greater skepticism (Cano-Orón; Mendoza-Poudereux; Moreno-Castro, 2019). Based on the fact that in Spain $75 \%$ of the adult population (16-49 years old) gets information about health on the Internet (Ontsi, 2017) and that this medium is the second main source of information for homeopathy consumers (Cano-Orón; Mendoza-Poudereux; Moreno-Castro, 2018), we wonder:

(Q1) What resources does Google offer about homeopathy through SERPs? Does the ranking vary over time? What type of content does Google index as more relevant?

(Q2) What vision does Google generate from its SERPs? Are there differences in the discourse on the effectiveness of homeopathy among the best positioned results?

Also, taking into account that algorithm automation and language processing works best in English (Arif et al., 2018), one may wonder:

(Q3) Are there similarities between searches carried out in the same language in different countries?

On the other hand, Google opts for algorithms that help optimize SERPs that, based on user behavior, seem to better satisfy the queries. Among others, location is a key factor for algorithms that Google uses to rank its search results (Kao, 2017). For this reason, and also in relation to the indications of other studies (Ballatore, 2015; Gerhart, 2004), the following question arises when dealing with controversial issues:

(Q4) Is the trend about homeopathy effectiveness that the first search results offer related to the climate of public opinion about this existing in the country?

The hypothesis on which this research is based is that the tendency of the position against homeopathy effectiveness is directly related to the general opinion of the country. So, in countries where homeopathy has a good image and is integrated as one more health option, the search results from the first positions confirm that positive view of homeopathy. Likewise, it is presumed that the best positioned results are stable over time and that they belong to reference pages and specialized health agencies.

When searching a controversial health issue, the type of content and the position on the topic of the best positioned websites have a determining potential to form the user's opinion

The general objective is to analyze the differences and the type of access to the information that Google provides on a subject as controversial as the use of the homeopathy depending on the language and geographical location.

\section{Dr. Google: Biases and effects}

Googling allows access to a series of websites that are selected by the thematic relationship that the user has requested. It also enables to appreciate the infinite extension of the infosphere, offering thousands of websites to consult to satisfy the search. This ordering of results fulfills the function of information gatekeeper (Haim; Arendt; Scherr, 2017, Germano; Sobbrio, 2017, Rieder; Sire, 2014) or digital intermediary (Kleis-Nielsen; Ganter, 2018), even if it is "algorithmic and virtual" (Gonzalo-Penela, 2015, p. 79). 
However, as Rieder and Sire (2014) point out, Google must be analysed beyond its media work and keeping in mind the economic perspective, since it combines user satisfaction with advertising services. In this sense, the Google search engine is a three-sided market, since it has to satisfy users, content providers and advertisers. In this sense, it is necessary to take into account as context data of this research that the pharmaceutical and health sector spends the least in advertising than any other, representing $0.8 \%$ (IAB Spain, 2017) of investments in advertising in Spain (about $€ 44.12$ million). It should also be understood that the Spanish regulation on the health services and products advertising is more restrictive and that Google Ads in Spain does not allow the creation of campaigns that promise specific results. ${ }^{1}$ This contrasts with the 2.84 billion dollars that the sector in the US invests in digital advertising, of which $37.1 \%$ is dedicated exclusively to search ads (Del-Gigante, 2018).

Likewise, and regarding the scope of content providers, one must also take into account their desire to be algorithmically recognizable (Gillespie, 2014; 2017), applying SEO techniques to please algorithms and be chosen to hold the first ranking positions, which are the ones that receive the most views (Gonzalo-Penela, 2015; Lee, 2005). Due to the opacity with which Google protects its algorithms (Pasquale, 2015; Gillespie, 2017), it is not possible to know exactly the formula they use to order the results, but it is known that there is the influence of certain factors that make search results not global, although they may seem so (Jiang, 2014a; 2014b).

Elements that influence the ranking are the language, the wording, the popularity of the site, the clicks (Jiang, 2014b). As for the popularity factor, which is very important, it also falls into the dynamics that, obviously, if the sites that receive the most visits are the first ones, with those visits they reinforce their popularity, following the rich-get-richer dynamics. In this case, the popularity of the site is rewarded, and not its content (Rieder; Sire, 2014; Díaz, 2008).

Another parameter that also influences the selection and ordering of websites for users is the location from which they perform the search (Gonzalo-Penela; Codina; Rovira, 2015; Haim; Arendt; Scherr, 2017), which is known via the IP address of the computer or the cell phone geolocation. This condition causes the results, far from being cross-border contributions, to be linked to local information and publicity, what Jiang (2014a; 2014b) calls search parochialism. In fact, even if searches are performed on Google.com, if you are in Spain, for example, they will be performed by default on Google.es (Kao, 2017).

Any search engine, by ordering the webs and giving priority to some contents over others, already offers a biased view (Lewandowski, 2017; Rieder; Sire, 2014; Jiang, 2014b) or one of the multiple visions of the web (Koed-Madsen, 2016), but the factors taken into account by Google to personalize the search results constitute an extra bias that is invisible to the user. Haim; Graefe; Brosius (2018) indicate that this personalization, depending on the user's data, is present but that it does not isolate the subjects in a bubble, nor completely reduces the range of opinions. In the political sphere, a suppression of different points of view has not been found either (Robertson; Lazer; Wilson, 2018, Puschmann, 2018). However, it has been detected that Google, specifically Google News, offers greater prominence to some media and marginalizes others (Haim; Graefe; Brosius, 2018).

Algorithms interpret and reproduce culture (Roberge; Melaçon, 2017), identify a social tendency and adapt to it, learn to identify and recreate stereotypes (Baker; Potts, 2013). From machine learning techniques, which are based on the behavior data of many users, algorithms make decisions and create a we (Ananny, 2016), a monoculture (Bozdag, 2013). These algorithms not only respond to the users use and behavior, but also reflect the biases of the designers of these algorithms (Noble, 2018).

In the case of searches on health, the biases that can occur are determinant for users, as one of the problems detected when consulting Dr. Google is that the more you look for the less you trust the doctor (Van-Riel et al., 2017). Regarding the effects of search results users find, we must bear in mind that these have a great influence on decision making (Pogacar et al., 2017) and that the dominant response can be decisive (White, 2014).

Pogacar et al. (2017) detect that users are predisposed to find positive information about the treatments on which they seek information, so they are also liable to be influenced by confirmation bias. The fact that users are not aware of the biases derived from the algorithm increases their susceptibility to a cognitive bias (influence from graphic and contextual information), which increases the influence of the source point of view (Novin; Meyers, 2017).

The specific weight of search results is avoided when the user has prior scientific knowledge of the treatment on which information is sought on the Internet (Pogacar et al., 2017). Likewise, it also depends on the level of conviction of this prior knowledge and the reliability that the source that is being consulted suggests to the user (Kammerer et al., 2013).

From the studies that have been conducted on SERPs biases in health searches, it can be inferred that, on the one hand, the valence of the words conditions the results (Ruiz; Bell, 2014; Pías-Peleteiro; Cortés-Bordoy; Martinón-Torres, 2013), so that if the search for a treatment followed by the word "risk" is performed, the first results will show negative information, while if you add "benefits" the best positioned pages will be those that promote the use of that treatment. In the case of not using a specific valence for the search, White and Hassan (2014, p. 26) detected in Bing a tendency of the ranking towards positive information regarding a treatment, although it was not strictly true. 
When looking at controversial issues, we find opposing positions. On the one hand, Gerhart (2004) warns that the diversity of voices participating in a controversy is visible in Google when it is a hot topic, while in controversies that have not received attention from the public opinion, the diversity of opinion does tend to be deleted from the results. However, on the other hand, Ballatore (2015) disagrees about the perpetuation of a majority opinion on the part of the search engine, but at the same time does consider the analysis of search results as a mirror to analyze society.

No study has been found that crosses the two ideas derived from the studies of Gerhart (2004) and Ballatore (2015), in which the diversity of opinion in the ranking is analyzed and if this diversity works as a reflection of society. However, it is public that Google strives to provide more accurate results to the citizens' queries. With this objective, based on tools such as the Knowledge graph, or Hummingbird and RankBrain algorithms, Google processes users' search behavior regarding specific searches and the quality of the websites to improve the positioning of those results that seem to better satisfy citizens (Lopezosa; Codina; Caldera-Serrano, 2018), determined by their location (Kao, 2017). This type of elements that Google takes into account could generate that social mirror (Ballatore, 2015) representing the diversity of voices that participate in a controversy (Gerhart, 2004).

\section{Methodology}

The corpus used for this research is made up of the best positioned web pages according to the relevance granted by Google. The ranking obtained is the closest thing that can be to what a common user would find, since it is understood that this ranking by "relevance" is the application of the factors that Google takes into account to establish its ranking; such as, for example,

- the popularity of the website -one of the most determining factors for the web's assessment by the algorithm-,

- the novelty,

- the adequacy with the search and the location (Lewandowski, 2017),

except for the customization factor of the user profile.

Starting with the Google Scraper ${ }^{2}$ tool, used with a browser in incognito mode, the first 20 results of three homeopathy searches were compiled in the main languages of the following countries:

- Spain and Mexico (in Spanish),

- France (in French),

- the United Kingdom and the United States (in English).

In this way results could be compared in the same language in different locations, as well as the difference between Europe and America. The choice of these countries is justified by their different policies towards homeopathy and their cultural differences.

- Spain and the United Kingdom are characterized by having a strong skeptical movement;

- France, both socially and legislatively, has integrated homeopathy into its health system;

- the US and Mexico represent intermediate case studies, in which homeopathy does not have much presence.

Four waves of data collection were carried out during 2018 in order to observe if ranking alterations were frequent. In particular, data were downloaded dated January 1, March 1, May 1 and July 1, thus comprising a period of seven months.

The selection of the keywords to perform the searches was based on the Google Autocomplete data with the application AnswerThePublic:

https://answerthepublic.com

This tool offers around 200 search proposals derived from the chosen keyword. These proposals come from the Google Autocomplete data, which are the suggestions made to users when they start typing their search, according to the number of similar searches previously made. In our case, the general descriptor "homeopathy" was used in the three analyzed languages. In this way, not only are similar searches chosen among the different languages, but formulated in the most widely used way in that language (Table 1). The problem that underlies this type of formulation is that it is not usually grammatically correct. This can be quickly checked by searching with Google Trends; the difference in traffic between emphasized and non-emphasized keywords is considerable. However, it is decided to choose this combination of words because it is the most usual way to perform the search, and, therefore, what more users would find.

Table 1. Keywords used for searches

\begin{tabular}{|c|c|c|c|c|c|}
\hline \multirow{3}{*}{$\begin{array}{l}\text { Language } \\
\text { Country }\end{array}$} & \multicolumn{2}{|c|}{ Spanish } & \multicolumn{2}{|l|}{ English } & French \\
\hline & Spain & Mexico & United Kingdom & United States & France \\
\hline & \multicolumn{2}{|c|}{ homeopatia } & \multicolumn{2}{|l|}{ homeopathy } & homeopathie \\
\hline \multirow[t]{2}{*}{ Search terms } & \multicolumn{2}{|c|}{ homeopatia que cura } & \multicolumn{2}{|c|}{ what homeopathy can treat } & que soigne homeopathie \\
\hline & \multicolumn{2}{|c|}{ homeopatía como funciona } & \multicolumn{2}{|c|}{ how homeopathy works } & homéopathie comment ça marche \\
\hline
\end{tabular}


Likewise, in order to discover the existing level of competence to position a web page in the first ranking, the Google word search "homeopathy" in the selected languages and countries has been performed. This information is relevant because it reflects the value that a key word has in the market. That is, it allows you to have an idea of whether there are many or few people interested in improving the visibility of your website through advertising techniques.

Of the total of webs collected, 1,200 webs, there are a total of 264 unique URLs. That is to say, that regardless of their ranking positioning over time the most relevant webs do not vary much.

Table 2. Variables and categories used in content analysis

\begin{tabular}{|c|c|c|}
\hline Type of website & Description & Example \\
\hline Reference works & Dictionaries, encyclopaedias, webs that offer definitions & wikipedia.org; definicionabc.com \\
\hline Specialized health portals & $\begin{array}{l}\text { They post information on health in general (thematic forum), or } \\
\text { develops specific explanations on doubts and therapies }\end{array}$ & topsante.com; saludymedicinas.com.mx \\
\hline Government & Belonging to a government entity, such as the Ministry of Health & nhs.uk; mscbs.gob.es \\
\hline Advertising & $\begin{array}{l}\text { Its purpose is selling: website of the application center, courses } \\
\text { offered, etc. }\end{array}$ & boiron.es; homeopathic.com \\
\hline Professionals & Belonging to professional organizations & homeopatia-si.es; sefac.org \\
\hline $\begin{array}{l}\text { Non-professional } \\
\text { organisations }\end{array}$ & $\begin{array}{l}\text { Organizations (mobilized with the theme or not) that are not } \\
\text { described as sector professionals. NGOs, associations, societies, } \\
\text { foundations, etc. }\end{array}$ & queeslahomeopatia.com; 1023.org.uk \\
\hline News & Media & eldiario.es; sante.lefigaro.fr \\
\hline Academic paper & Websites / documents on scientific journals & ncbi.nlm.nih.gov; scielo.org \\
\hline \multicolumn{3}{|l|}{ Other } \\
\hline Homeopathy stance & Description & \\
\hline In favour of & $\begin{array}{l}\text { Presence of arguments that consider homeopathy as an effecti- } \\
\text { ve therapy }\end{array}$ & $\begin{array}{l}\text { https://www.hablandodehomeopatia.com/el-miedo- } \\
\text { que-nos-enferma-y-la-homeopatia-que-nos-cura }\end{array}$ \\
\hline Against & $\begin{array}{l}\text { Presence of arguments that challenge the effectiveness of } \\
\text { homeopathy }\end{array}$ & http://queeslahomeopatia.com \\
\hline Neutral & Without clear positioning & http://news.bbc.co.uk/2/hi/talking_point/4187412.stm \\
\hline Presence of controversy & Description & \\
\hline Yes & $\begin{array}{l}\text { Arguments are used for and against homeopathy making it clear } \\
\text { that there is a controversy }\end{array}$ & http://www.quo.es/salud/homeopatia-funciona-no \\
\hline No & A unique stance is taken on the effectiveness of the homeopathy & http://www.boiron.es/homeopatia-que-es \\
\hline \multicolumn{3}{|l|}{ Not applicable } \\
\hline Content & Description & \\
\hline Information & Data and explanations are provided & $\begin{array}{l}\text { https://www.britishhomeopathic.org/ } \\
\text { homeopathy/what-is-homeopathy }\end{array}$ \\
\hline Opinion / testimony & It is argued from patient testimonies or used as a resource & $\begin{array}{l}\text { https://www.vice.com/es_latam/article/534kbd/ } \\
\text { homeopatia-curar-lesbianismo-lgbtq-homofobia }\end{array}$ \\
\hline Hybrid & Presence of explanations and opinions / testimonies & $\begin{array}{l}\text { http://lab.elmundo.es/pseudociencias/homeopatia. } \\
\text { html }\end{array}$ \\
\hline
\end{tabular}

With this corpus, the fluctuation of the ranking is analyzed with RankFlow (Rieder, 2016). This tool displays the web pages position in each ranking, allowing to easily observe how their positioning evolves in the different waves. Likewise, it also allows to calculate the "rank-biased distance" (distance of the positioning of the components among several rankings), that is, how much variation there is between one ranking and another.

A content analysis based on variables adapted from the studies of León and Codina (2016) [content variable] and Arif et al. (2018) [the type of web variable], both of them similar to the present study, and others ad hoc (Table 2) is applied to a corpus sample.

The sample consists of the first 10 pages of each search belonging to the last wave (July 2018). This is because, on the one hand, they are the most recent, and, on the other, because they are the most visited (Lee, 2005). In total, 150 pages are analyzed ( 5 countries $x 3$ search terms x 10 first pages). The 3 search terms are "homeopathy", "what homeopathy can treat" and "how homeopathy works".

For coding, a postdoctoral researcher was asked to code $30 \%(n=46)$ of the sample to be able to perform a reliability test. After two meetings to finish defining the categories, the Cronbach's Alpha reliability test reached an optimal result for all the variables:

- "Medium type" = 1

- "Homeopathy stance" $=0.95$

- "Presence of controversy" = 0.92

- "Content" = 0.92 


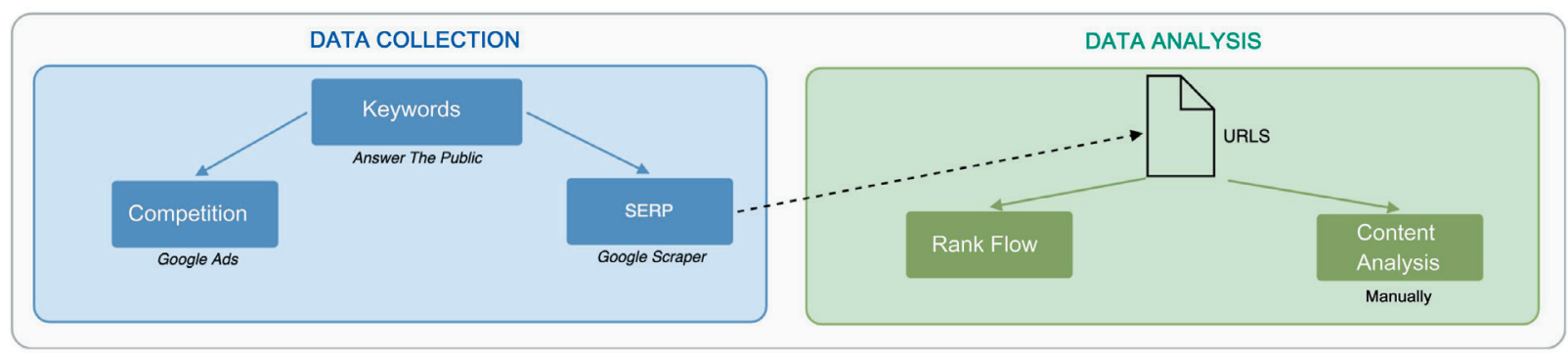

Figure 1. Method applied to this study

\section{Results}

\subsection{Competition for keywords positioning (Google Ads)}

The positioning of websites and / or ads from the economic bidding for the keyword "homeopathy" in different countries and languages shows a low level of competition, in accordance with the data offered by Google Ads. That is, despite being an expensive keyword, due to the number of searches performed per mon-

Table 3. Google Ads data

\begin{tabular}{|l|c|c|c|c|c|c|}
\hline \multicolumn{1}{|c|}{ Keyword } & Country & $\begin{array}{c}\text { Min. } \\
\text { monthly } \\
\text { searches }\end{array}$ & $\begin{array}{c}\text { Max. } \\
\text { monthly } \\
\text { searches }\end{array}$ & $\begin{array}{c}\text { Competi- } \\
\text { tion }\end{array}$ & $\begin{array}{c}\text { Bid (low } \\
\text { interval) }\end{array}$ & $\begin{array}{c}\text { Bid (high } \\
\text { interval) }\end{array}$ \\
\hline homeopatía & Spain & 10.000 & 100.000 & Low & $0,15 €$ & $0,60 €$ \\
\hline homeopatía & Mexico & 10.000 & 100.000 & Low & $0,02 €$ & $0,15 €$ \\
\hline homeopathie & France & 10.000 & 100.000 & Low & $0,20 €$ & $0,67 €$ \\
\hline homeopathy & United Kingdom & 10.000 & 100.000 & Low & $0,25 €$ & $0,91 €$ \\
\hline homeopathy & United States & 10.000 & 100.000 & Low & $0,05 €$ & $2,04 €$ \\
\hline
\end{tabular}

th, there are not many entities

paying for it. In fact, when the search is performed, ads do not usually appear. However, if we look at data (Table 3), it is anecdotal to note that the highest bid values ${ }^{3}$ also correspond to the order of the per capita income value of the countries. ${ }^{4}$

Other keywords, not studied here, do seem to concentrate the investments of stores specializing in homeopathy, such as "homeopathy buy" and "homeopathy products".

\subsection{Fluctuation of the websites in the ranking over time (RankFlow)}

After comparing the fluctuation of the positioning of the web pages in the Google ranking in four different waves (Figures $2 a$ and $2 b$ ), we can affirm that there is a general stability in the positioning over time: the average distance of the ranking deviation is minimal or null in all cases. The only ranking that changes the most is the one re-
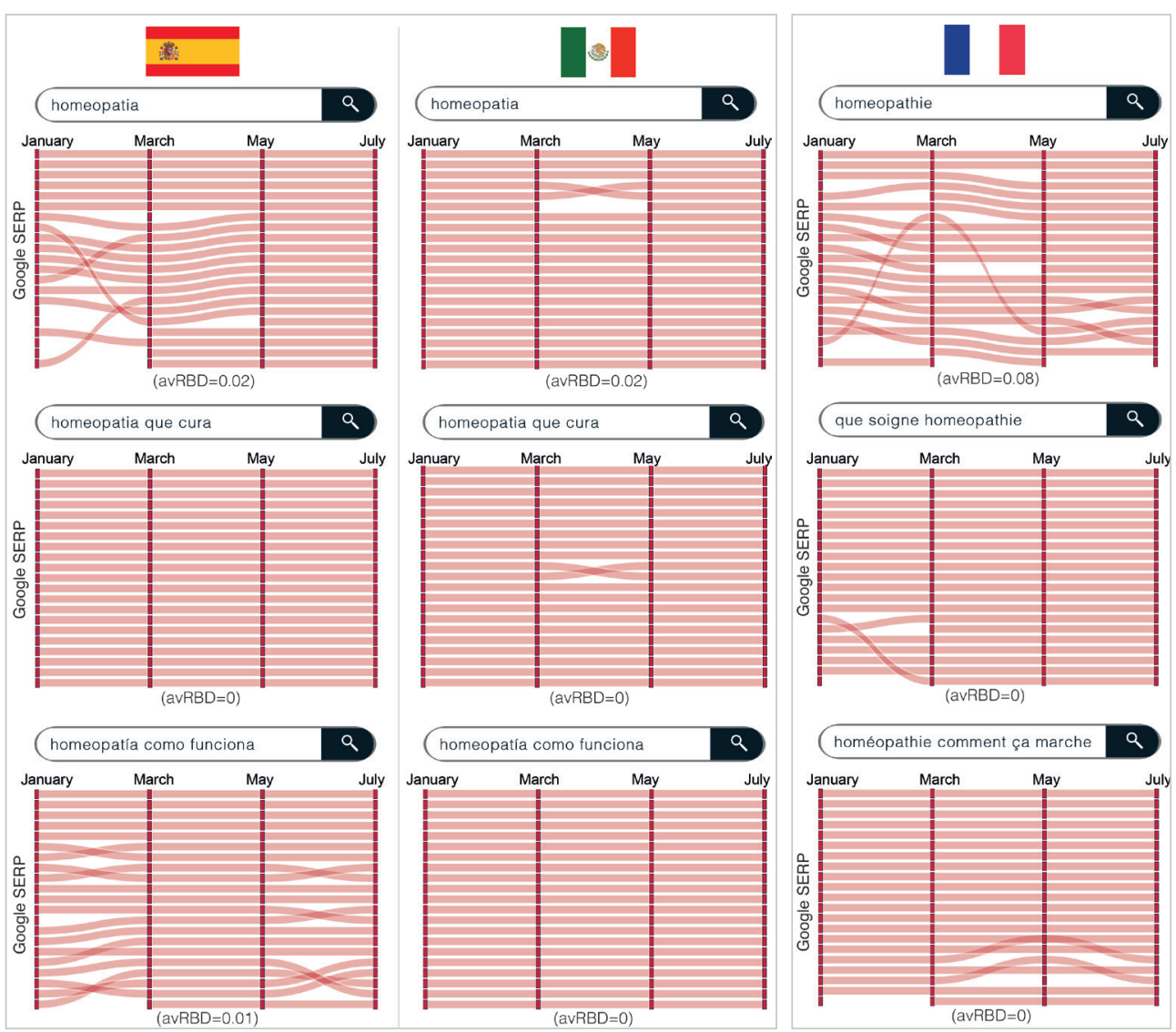

Figure 2a. Fluctuation of the first 20 results in rankings. January-July 2018. Spain, Mexico and France.

The four red bars correspond to the four waves of the study. $a v R B D=$ Average ranking distance of the ranking deviation 
lated to the "homeopathie" search results in France, with an average deviation of 0.08 . Even so, the distance is still smaller (this metric has a maximum of 1). Also, visually you can also see how the web pages that appear in the first positions remain in place over time.

\subsection{What webs are better positioned and what vision do they offer (content analysis)}

The most present website type in the first Google results belongs to the media (Table 4). News is the most abundant format, by far, in the results of the five countries. The specialized health portals, organizations websites and health professionals are also very present in general, although the proportion of this type of website varies greatly depending on the country, where in some cases it does not even appear in the most prominent results.

It is observed that, in general, there is an almost absolute lack of governmental portals; only in the United Kingdom a single portal appears among the most popular websites. In the case of reference websites the same thing happens: portals such as Wikipedia and different dictionaries are not among the first positions.

If we observe the data (Table 4) from a linguistic point of view, there are no common patterns beyond the wide presence of news, a feature shared by all countries. We can make comparisons by linguistic blocks: for example, see how in English (US + GB) websites of non-professional organizations are more common (11 out of 60 ) than in Spanish-speaking results (ES + MX) (4 out of 60) and than in the results in French, where they are not even present. But if we look at the coherence between the proportions of the same linguistic block, we observe that there is no common pattern.

If we observe the data (Table 4) from a geographic point of view, distinguishing Europe (ES + FR + GB) from America (US $+M X$ ), they do not show a similar distribution regarding the website type. So neither the language nor the geographical approach seem to be determining factors.

Regarding the type of content (Table 5) offered by the websites analyzed, the presence of information is the majority (133/150). The number of websites that build their content mixing information and testimo-
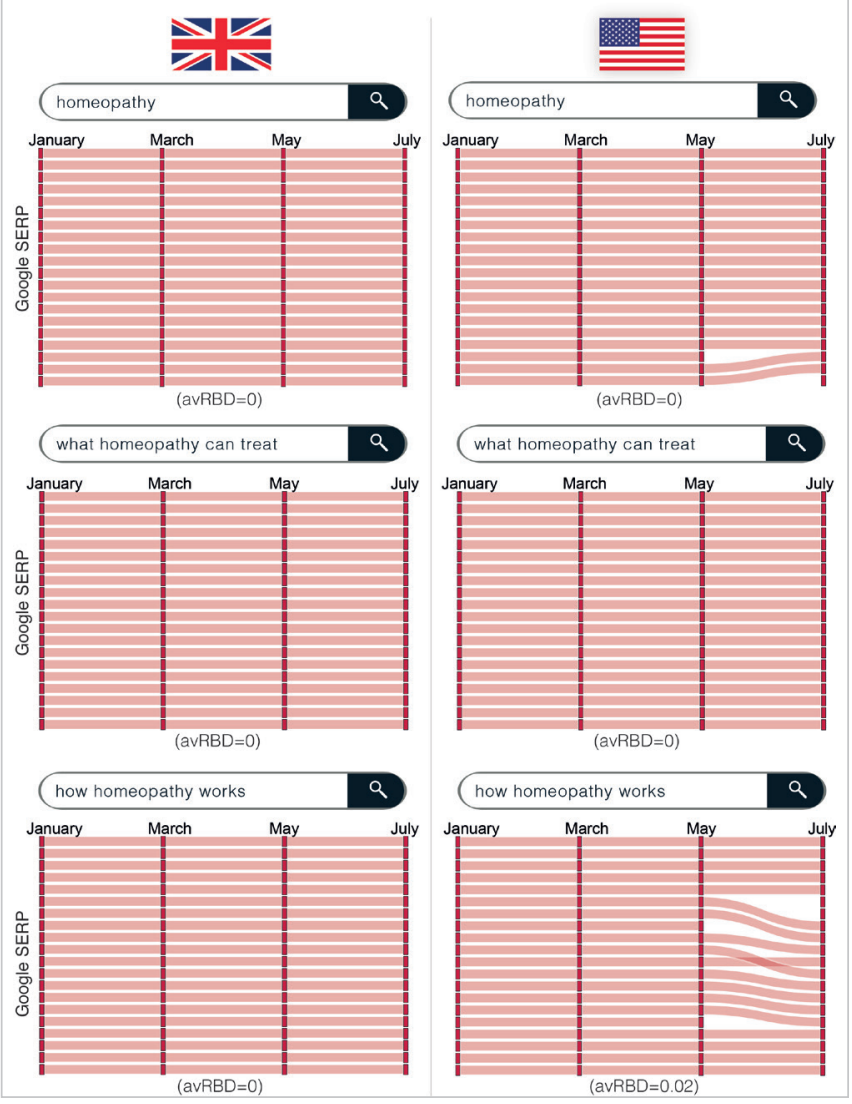

Figure 2 b. Fluctuation of the first 20 results in rankings. January-July 2018 . United Kingdom and United States.

The four red bars correspond to the four waves of the study. $a v R B D=$ Average ranking distance of the ranking deviation

Table 4. Better positioned website types by country

\begin{tabular}{|l|r|r|r|r|r|r|}
\hline \multicolumn{1}{|c|}{ Media type } & ES & US & FR & MX & GB & Total \\
\hline Academic paper & 0 & 2 & 0 & 1 & 1 & 4 \\
\hline Government & 0 & 0 & 0 & 0 & 1 & 1 \\
\hline News & 11 & 10 & 11 & 17 & 14 & 63 \\
\hline Reference works & 0 & 0 & 0 & 1 & 0 & 1 \\
\hline $\begin{array}{l}\text { Non-professional } \\
\text { organizations }\end{array}$ & 4 & 3 & 0 & 0 & 8 & 15 \\
\hline Specialized health portals & 4 & 5 & 9 & 4 & 0 & 22 \\
\hline Health professionals & 6 & 4 & 1 & 0 & 6 & 17 \\
\hline Advertising & 2 & 4 & 4 & 3 & 0 & 13 \\
\hline Other & 3 & 2 & 5 & 4 & 0 & 14 \\
\hline Total & 30 & 30 & 30 & 30 & 30 & 150 \\
\hline
\end{tabular}

Table 6. Presence of controversy in the webs best positioned by country

Table 5. Type of content of the best positioned websites by country

\begin{tabular}{|l|c|c|c|}
\hline \multicolumn{1}{|c|}{ Country } & Hybrid & Information & Opinion / testimony \\
\hline Spain & 8 & 22 & 0 \\
\hline United States & 3 & 26 & 1 \\
\hline France & 0 & 30 & 0 \\
\hline Mexico & 1 & 28 & 1 \\
\hline United Kingdom & 3 & 27 & 0 \\
\hline Total & 15 & 133 & 2 \\
\hline
\end{tabular}

\begin{tabular}{|l|c|c|}
\hline Country & No & Yes \\
\hline Spain & 24 & 6 \\
\hline United States & 18 & 12 \\
\hline France & 23 & 7 \\
\hline Mexico & 28 & 2 \\
\hline United Kingdom & 24 & 6 \\
\hline Total & 117 & 33 \\
\hline
\end{tabular}


nies or opinion is anecdotal (15/150); of which, most are news (12/15) and health professionals' portals (3/15). As for those websites that only offer opinions or testimonials, their incidence in the rankings is minimal (2/150).
Only in the United Kingdom does a government website appear among the most popular

In this work we have also measured the presence of con-

troversy or, in other words, the visibility of the fact that we are dealing with a topic with two antagonistic positions. In this case, most websites $(117 / 150)$ do not include in their content the existence of a possible controversy regarding the information they are disseminating.

Regarding how homeopathy is shown as an effective therapy, in view of the results (Figure 3), it is still not possible to establish a pattern by language or geographical area, because, although Spain and the United Kingdom have a higher percentage of websites positioned against homeopathy, France does not follow this pattern.

On the other hand, with this variable, the relationship between the country's general positioning towards this therapy and its position in the health system and the perspective adopted by the most popular websites is clearly evident. Both Spain and the United Kingdom are countries in which skepticism is increasing in public opinion, as can be inferred from the information and opinions disseminated in the media and social networks, with very active campaigns against homeopathy. Such opposition is visible with a greater presence of websites with negative content about this alternative therapy. The reverse happens in France, a country where historically there has been a greater acceptance of homeopathy, and therefore presents a majority of websites in favor of it. In fact, if we talk about the probability that a user has of finding one type of stance or another (Table 7 ), noteworthy is how in France there is an $80 \%$ chance of finding a website in favor of homeopathy in the first Google results. Similar is the case of the US, where there is also a $73 \%$ chance that a user will find content in favor of homeopathy. Less frequently, but more likely to find websites in favor of homeopathy than against it, is the case of Mexico, with $67 \%$ of websites in favor of it. The opposite cases, where it is more frequent to find information against homeopathy, are the United Kingdom, with 63\%, and Spain with 53\%.

\section{Discussion and conclusions}

In the analyzed case, the most relevant websites and, therefore, better positioned in Google do not

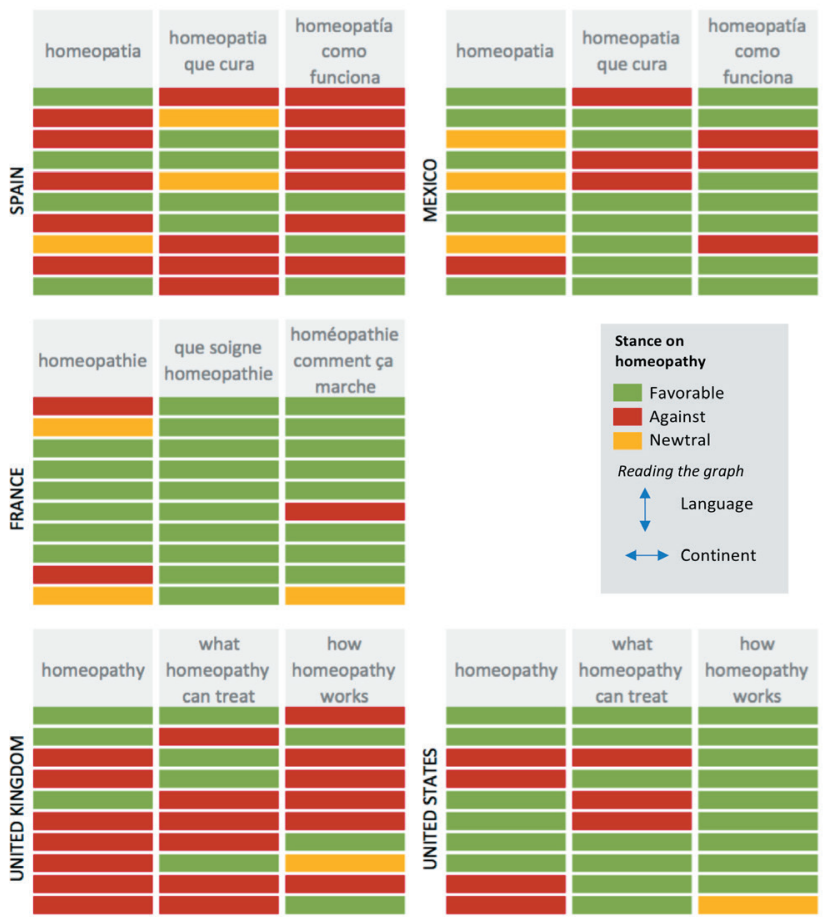

Figure 3. General stance towards homeopathy by the websites in the rankings. The websites are ordered following the SERP ranking. On the left hand side is Europe and on the right America. Above is the Spanish language, then French and below English.

Green = in favour of homeopathy; Yellow = neutral; Red = against it.

Table 7. Relative frequencies of the homeopathy stance of the websites analyzed

\begin{tabular}{|l|c|c|c|}
\hline \multicolumn{1}{|c|}{ Country } & Favorable & Against & Neutral \\
\hline Spain & $37 \%$ & $53 \%$ & $10 \%$ \\
\hline France & $80 \%$ & $10 \%$ & $10 \%$ \\
\hline United Kingdom & $33 \%$ & $63 \%$ & $3 \%$ \\
\hline United States & $73 \%$ & $23 \%$ & $3 \%$ \\
\hline Mexico & $67 \%$ & $23 \%$ & $10 \%$ \\
\hline
\end{tabular}
have hardly changed. This could be due to richer-get-richer dynamics (Rieder; Sire 2014; Díaz, 2008), which make the most visited websites the best positioned as well.

The content that has had the most presence in the different analyzed rankings has been the news, as in the studies of Arif et al. (2018) and Puschmann (2018). It could be expected that reference websites such as Wikipedia or a dictionary would have been common in the best positions, but surprisingly this is not the case, since of all the websites of the sample (150), only one of them appears among the 10 most relevant pages, in the United Kingdom ranking.

Given this situation, it is logical to think that the position taken by the press also contributes actively to the algorithmic bias that is created with the SERPs. In fact, in the case of Spain, in which the press, increasingly, treats homeopathy with a greater degree of skepticism (Cano-Orón; Mendoza-Poudereux; Moreno-Castro, 2019), 53\% of the websites 
show a stance against its effectiveness. Spain is the second country analyzed with the highest negative bias, only behind the United Kingdom, where it is more likely to find skeptical information about the effectiveness of homeopathy in the best ranking positions.

The various stances on the effectiveness of the homeopathy found in the rankings matches the country situation. In this case, there is no full polarization of the results and, therefore, no algorithm attempt to suppress the controversy, although there is a certain bias that simulates the climate of public opinion in each country. Therefore, SERPS biases can be understood as reflecting the favorable or unfavorable position of users (Ballatore, 2015), or as the bias derived from user learning and the creation of monoculture (Roberge; Melaçon, 2017; Baker; Potts, 2013; Bozdag, 2013).

This similarity found between the search results and the state of public opinion could also be due to SEO positioning of the media appearing in the first results, but also to the popularity and relevance of each link, judged by algorithms from the reactions of many users performing those queries and choosing some links or the others.

Location is, therefore, a determining factor in the type of results offered by Google. On the contrary, different countries with the same language have no similarities between them. That is to say, the search language is a determining factor regarding that the recovered pages will be in that information, but the most determining factor is the origin. This reinforces the concept of "search parochialism" (provincialist search) by Jiang (2014a; 2014b), because $a$ priori the idea of searching the Internet seems unlimited and then it turns out to respond to factors linked to geographical borders. So, confirming our starting hypothesis, it does not receive the same type of content or stance on homeopathy a person who searches from Spain than one who does it from another country.

One of the limitations of this study is that the analysis material is artificial, that is, it is like a laboratory, because the user experience, with each one's cookies, can not be recreated; it depends on many factors. Therefore, the links studied here represent an artificial ranking that includes the most popular sites classified by Google, which is understood to appear among the first results of any user. The image of the results analyzed here is not $100 \%$ accurate regarding the one that would be sent to each and every one of the users.

However, it is an exploratory study that shows some interesting indicators for future research, such as the confirmation that both in the selected sample of countries and in the terminological selection there is a relationship between the contemporary social debate and the results thrown by the first pages of Dr. Google. Data that are sensitive to the terminological indicators with a value charge, such as when the words "risk" or "benefit" are used, as demonstrated by Ruiz and Bell (2014) and Pías-Peleteiro, Cortés-Bordoy and Martinón-Torres (2013). The identification of this pattern could be revealing for the design of contents of institutional pages with health information, which currently rank low. In the sample of pages analyzed, the greatest volume of information comes from media pages, and not from institutional pages.

Therefore, the favorable or critical tendency in the media in each of the countries studied has marked, to a large extent, the bias of the pages that the search engine has selected from the searches of the users.

Likewise, it is necessary to take into account in this specific topic that neither the number of publications in the media nor the searches on Google on alternative therapies are directly related to the consumption of these by the population (Moreno-Castro; Lopera-Pareja, 2016; Cano-Orón, 2016; Cano-Orón; Mendoza-Poudereux; Moreno-Castro, 2018). However, the impact of these searches when setting up the opinion is key.

From the data obtained here, many more questions arise that should be addressed in future research. For example, it would be interesting to determine how the public opinion cycle works:

- Are the media the ones that set the Google agenda?

- Is the type of regulation that exists in each country the symptom or precursor of public opinion?

- Are the users the ones that determine the Google agenda when falling into the confirmation bias?

And in addition to all these questions that could be of a general nature and widely studied by communication and public opinion theorists, it would be interesting to analyze them in a socially controversial topic such as homeopathy, since it is an unknown whether it would follow the same pattern of influences and interactions that the rest of the issues or other factors at stake.

\section{Notes}

1. To learn more about the Google Ads regulation in relation to health care and drugs: https://support.google.com/adspolicy/answer/176031?hl=es 
2. Free web application developed by researchers at the University of Amsterdam within the framework of the Digital Methods Initiative:

https://tools.digitalmethods.net/beta/scrapeGoogle

3. Bid values fluctuate according to competition. The minimum value refers to the minimum cost that the person responsible will assume for every thousand visible impressions (VCPM) or click (CPC) that your website has. The high interval marks the maximum price of the bid, in relation to the competitors participating in the auction.

4. According to the World Bank, 2017:

- United States: $\quad \$ 59,531.7$

- United Kingdom: $\$ 39,720.4$

- France: $\quad \$ 38,476.7$

- Spain: $\quad \$ 28,156.8$

- Mexico: \$8,902.8

https://data.worldbank.org/indicator/ny.gdp.pcap.cd

\section{References}

Allam, Ahmed; Schulz, Peter-Johannes; Nakamoto, Kent (2014). "The impact of search engine selection and sorting criteria on vaccination beliefs and attitudes: Two experiments manipulating Google output". Journal of medical internet research, v. 16, n. 4.

https://doi.org/10.2196/jmir.2642

Ananny, Mike (2016). "Toward an ethics of algorithms: Convening, observation, probability, and timeliness". Science, technology \& human values, v. 41, n. 1, pp. 93-117.

https://doi.org/10.1177/0162243915606523

Arif, Nadia; Al-Jefri, Majed; Bizzi, Isabella H.; Boitano-Perano, Gianni; Goldman, Michel; Haq, Inam; Chua, Kee-Leng; Mengozzi, Manuela; Neunez, Marie; Smith, Helen; Ghezzi, Pietro (2018). "Fake news or weak science? Visibility and characterization of antivaccine webpages returned by Google in different languages and countries". Frontiers in immunology, v. 9.

https://doi.org/10.3389/fimmu.2018.01215

Baker, Paul; Potts, Amanda (2013). "'Why do white people have thin lips?' Google and the perpetuation of stereotypes via auto-complete search forms". Critical discourse studies, v. 10, n. 2, pp. 187-204.

https://doi.org/10.1080/17405904.2012.744320

Ballatore, Andrea (2015). "Google chemtrails: A methodology to analyze topic representation in search engine results". First Monday, v. 20, n. 7. https://doi.org/10.5210/fm.v20i7.5597

Bozdag, Engin (2013). "Bias in algorithmic filtering and personalization". Ethics and information technology, v. 15, n. 3, pp. 209-227. https://doi.org/10.1007/s10676-013-9321-6

Cano-Orón, Lorena (2016). “Correlación entre las búsquedas sobre terapias complementarias en Google y su uso por parte de la población española". Panace@, v. 17, n. 44, pp. 124-132.

https://dialnet.unirioja.es/servlet/articulo?codigo=5794532

Cano-Orón, Lorena; Mendoza-Poudereux, Isabel; Moreno-Castro, Carolina (2018a). “Perfil sociodemográfico del usuario de la homeopatía en España". Atención primaria.

https://doi.org/10.1016/j.aprim.2018.07.006

Cano-Orón, Lorena; Mendoza-Poudereux, Isabel; Moreno-Castro, Carolina (2019). "The rise of skepticism in the Spanish political and digital media contexts". JCOM. En prensa.

Del-Gigante, Michael (2018). "The state of healthcare advertising: 4 key digital spend trends". Mdgadvertising, July $24^{\text {th }}$. https://www.mdgadvertising.com/marketing-insights/the-state-of-healthcare-advertising-4-key-digital-spend-trends

Díaz, Alejandro (2008). "Through the Google Goggles: Sociopolitical bias in search engine design”. In: Spink, Amanda; Zimmer, Michael (eds). Web search. Multidisciplinary perspectives. Berlin: Springer, pp. 11-34. ISBN: 9783540758280 https://doi.org/10.1007/978-3-540-75829-7_2

Gerhart, Susan (2004). “Do web search engines suppress controversy?”. First Monday, v. 9, n. 1. https://doi.org/10.5210/fm.v9i1.1111

Germano, Fabrizio; Sobbrio, Francesco (2017). "Opinion dynamics via search engines (and other algorithmic gatekeepers)". https://doi.org/10.2139/ssrn.2890853 
Gillespie, Tarleton (2014). "The relevance of algorithms". In: Gillespie, Tarleton; Boczkowski, Pablo; Foot, Kirsten (eds.). Media technologies: Essays on communication, materiality, and society. Cambridge, MA: MIT Press, pp. 167-194. ISBN: 9780262525374

https://www.microsoft.com/en-us/research/wp-content/uploads/2014/01/Gillespie_2014_The-Relevance-of-Algorithms.pdf

Gillespie, Tarleton (2017). "Algorithmically recognizable: Santorum's Google problem, and Google's Santorum problem". Information, communication \& society, v. 20, n.1, pp. 63-80.

https://doi.org/10.1080/1369118X.2016.1199721

Gonzalo-Penela, Carlos (2015). Posicionamiento web y dinámicas de información en motores de búsqueda: propuestas de análisis y estudio comparativo de visibilidad de contenidos digitales en el caso de procesos electorales. Tesis doctoral. Barcelona: Universitat Pompeu Fabra.

http://hdl.handle.net/10230/23621

Gonzalo-Penela, Carlos; Codina, Lluís; Rovira, Cristòfol (2015). “Recuperación de información centrada en el usuario y SEO: categorización y determinación de las intenciones de búsqueda en la Web”. Index.comunicación: revista científica de comunicación aplicada, v. 5, n. 3, pp. 19-27.

http://journals.sfu.ca/indexcomunicacion/index.php/indexcomunicacion/article/view/197

Haim, Mario; Arendt, Florian; Scherr, Sebastian (2017). "Abyss or shelter? On the relevance of web search engines' search results when people google for suicide". Health communication, v. 32, n. 2, pp. 253-258.

https://doi.org/10.1080/10410236.2015.1113484

Haim, Mario; Graefe, Andreas; Brosius, Hans-Bernd (2018). “Burst of the filter bubble?”. Digital journalism, v. 6, n. 3, pp. 330-343.

https://doi.org/10.1080/21670811.2017.1338145

IAB Spain (2017). Inversión publicitaria en medios digitales. Resultados 2017.

https://iabspain.es/wp-content/uploads/inversin-publicitaria-medios-digitales_2017_vreducida.pdf

Jiang, Min (2014a). "Search concentration, bias, and parochialism: A comparative study of Google, Baidu, and Jike's search results from China". Journal of communication, v. 64, n. 6, pp. 1088-1110.

https://doi.org/10.1111/jcom.12126

Jiang, Min (2014b). "The business and politics of search engines: A comparative study of Baidu and Google's search results of internet events in China". New media \& society, v. 16, n. 2, pp. 212-233.

https://doi.org/10.1177/1461444813481196

Kammerer, Yvonne; Bråten, Ivar; Gerjets, Peter; Strøms $\varnothing$, Helge I. (2013). "The role of internet-specific epistemic beliefs in laypersons' source evaluations and decisions during Web search on a medical issue". Computers in human behavior, v. 29, n. 3, pp. 1193-1203.

https://doi.org/10.1016/j.chb.2012.10.012

Kao, Evelyn (2017). "Making search results more local and relevant". Google blog, 27 octubre. https://blog.google/products/search/making-search-results-more-local-and-relevant

Kleis-Nielsen, Rasmus; Ganter, Sarah-Anne (2018). "Dealing with digital intermediaries: A case study of the relations between publishers and platforms". New media \& society, v. 20, n. 4, pp. 1600-1617.

https://doi.org/10.1177/1461444817701318

Koed Madsen, Anders (2016). "Beyond the bubble: Three empirical reasons for re-conceptualizing online visibility". MedieKultur: Journal of media and communication research, v. 31, n. 59, pp. 6-27.

https://doi.org/10.7146/mediekultur.v31i59.19235

Lee, Kevin (2005). “Did-it, Enquiro and Eyetools uncover search's golden triangle". PRWeb, March $1^{\text {st }}$. https://www.prweb.com/releases/2005/03/prweb213516.htm

León, Bienvenido; Codina, Mónica (2016). "Information and opinion in the representation of scientific consensus and skepticism on climate change in Spanish language online publications". Observatorio (OBS*), v. 10, n. 3, pp. $104-118$. https://doi.org/10.15847/obsOBS10320161021

Lewandowski, Dirk (2017). “Is Google responsible for providing fair and unbiased results?”. In: Taddeo, Mariarosaria; Floridi, Luciano. The responsibilities of online service providers. Springer, Cham, pp. 61-77. ISBN: 9783319478524 https://doi.org/10.1007/978-3-319-47852-4_4

Lopezosa, Carlos; Codina, Lluís; Caldera-Serrano, Jorge (2018). “SEO semántico: Framework ISS para la optimización de sitios intensivos en contenidos". Cuadernos de documentación multimedia, v. 29, pp. 97-122.

http://revistas.ucm.es/index.php/CDMU/article/view/60607 
Moreno-Castro, Carolina; Lopera-Pareja, Emilia (2016). "Comparative study of the frequency of use of natural therapies among the Spanish population and their public image on digital media". In: Procs of $14^{\text {th }}$ Int conf on public communication of science and technology (PCST). Estambul, Turquía.

https://pcst.Co/archive/paper/2623

Noble, Safiya-Umoja (2018). Algorithms of oppression: How search engines reinforce racism. NYU Press. ISBN: 9781 479837243

Novin, Alamir; Meyers, Eric (2017). "Making sense of convicting science information: Exploring bias in the search engine result page". In: Proceedings of the 2017 Conf of human information interaction and retrieval. ACM, pp. $175-184$.

Ontsi (2017). La sociedad en Red. Informe anual 2016.

https://www.ontsi.red.es/ontsi/es/content/informe-anual-la-sociedad-en-red-2016-edici\%C3\%B3n-2017

Pan, Bing; Hembrooke, Helene; Joachims, Thorsten; Lorigo, Lori; Gay, Geri; Granka, Laura (2007). "In Google we trust: Users' decisions on rank, position, and relevance". Journal of computer-mediated communication, v. 12, n. 3, pp. 801823.

https://doi.org/10.1111/j.1083-6101.2007.00351.x

Pasquale, Frank (2015). The black box society: The secret algorithms that control money and information. Harvard University Press. ISBN: 9780674736061

Pías-Peleteiro, Leticia; Cortés-Bordoy, Javier; Martinón-Torres, Federico (2013). “Dr. Google: What about the human papillomavirus vaccine?". Human vaccines \& immunotherapeutics, v. 9, n. 8, pp. 1712-1719.

https://doi.org/10.4161/hv.25057

Pogacar, Frances; Ghenai, Amira; Smucker, Mark; Clarke, Charles L. A. (2017). "The positive and negative influence of search results on people's decisions about the efficacy of medical treatments". In: Kamps, Jaap; Kanoulas, Evangelos; De-Rijke, Maarten; Fang, Hui; Yilmaz, Emine. Procs of the ACM Sigir intl conf on theory of information retrieval. New York: ACM, pp. 209-216.

https://doi.org/10.1145/3121050.3121074

Puschmann, Cornelius (2018). "Beyond the bubble: Assessing the diversity of political search results". Digital journalism. https://doi.org/10.1080/21670811.2018.1539626

Ramaswami, Prem (2015). "A remedy for your health-related questions: Health info in the knowledge graph". Google. Official blog, Febr. 10.

https://googleblog.blogspot.com/2015/02/health-info-knowledge-graph.html

Rieder, Bernhard (2016). RankFlow.

http://labs.polsys.net/tools/rankflow

Rieder, Bernhard; Sire, Guillaume (2014). "Conflicts of interest and incentives to bias: A microeconomic critique of Google's tangled position on the Web". New media \& society, v. 16, n. 2, pp. 195-211.

https://doi.org/10.1177/1461444813481195

Roberge, Jonathan; Melançon, Louis (2017). “Being the King Kong of algorithmic culture is a tough job after all: Google's regimes of justification and the meanings of Glass". Convergence, v. 23, n. 3, pp. 306-324.

https://doi.org/10.1177/1354856515592506

Robertson, Ronald; Lazer, David; Wilson, Christo (2018). “Auditing the personalization and composition of politicaIly-related search engine results pages". In: Procs of the 2018 World Wide Web Conf on World Wide Web (pp. 955-965). International World Wide Web Conferences Steering Committee.

http://personalization.ccs.neu.edu/static/pdf/robertson-www18.pdf

Ruiz, Jeanette B.; Bell, Robert A. (2014). “Understanding vaccination resistance: Vaccine search term selection bias and the valence of retrieved information". Vaccine, v. 32, n. 44, pp. 5776-5780.

https://doi.org/10.1016/j.vaccine.2014.08.042

Van-Riel, Noor; Auwerx, Koen; Debbaut, Pieterjan; Van Hees, Sanne; Schoenmakers, Birgitte (2017). "The effect of Dr. Google on doctor-patient encounters in primary care: a quantitative, observational, cross-sectional study". BJGP open, v. 1 , n. 2. https://doi.org/10.3399/bjgpopen17X100833

White, Ryen (2014). "Belief dynamics in Web search". Journal of the Association for Information Science and Technology, v. 65, n. 11 , pp. $2165-2178$. https://doi.org/10.1002/asi.23128

White, Ryen; Hassan, Ahmed (2014). "Content bias in online health search". ACM transactions on the Web (TWEB), v. 8, n. 4, pp. 25.

https://doi.org/10.1145/2663355 